\title{
Backward extrusion of pipe workpieces from non-ferrous alloys with a cone-shaped punch
}

\author{
A. A. Pasynkov, Assistant Professor, Department of Mechanics of Plastic Forming ${ }^{1}$, sulee@mail.ru \\ V. I. Tregubov, Professor, Department of Mechanics of Plastic Forming ${ }^{1}$, tula@rambler.ru \\ O. I. Boriskin, Professor, Head of the Department of Instrumental and Metrological Systems ${ }^{1}$, mpf-tula@rambler.ru \\ ${ }^{1}$ Tula State University, Tula, Russia.
}

\begin{abstract}
The article presents the results of investigations of the backward extrusion operation of pipe workpieces to produce hollow thin-walled products with a changing cross-sectional area in the longitudinal direction. The process is very complex in terms of implementation, since considering various factors, this process can be carried out either with defects in the formation of geometry of the parts, or with significant forming forces, or with critical values of stresses and deformations. Therefore, the article presents the generalized research results on the pipe workpiece extrusion from $6 \mathrm{Al}-4 \mathrm{~V}$ non-ferrous titanium alloy. The results of the conducted studies have allowed determining the influence of geometric characteristics of a working tool, friction, degree of deformation, temperature and forming velocity on formation of the part geometry, forces and stress. A statistical study of the results obtained was performed. Secondary mathematical models that make it possible to estimate an impact of the considered parameters upon the power characteristics of operations are obtained. The forming velocity conditions, which allow to ensure minimum process forces and to provide prescribed geometric characteristics of the products given different process variables and parameters of the tool geometry, have been established by analyzing simulation results. The factors that are most affecting the folding under deforming tool are identified. The results obtained can be used as recommendations for manufacturing of cylindrical hollow products through implementation of backward extrusion.
\end{abstract}

Key words: backward extrusion, pipe workpiece, force, forming velocity, forming, cone-shaped punch.

DOI: $10.17580 / \mathrm{nfm} .2021 .01 .07$

\section{Introduction}

$\mathrm{P}$ roduction of the hollow cylindrical articles with a hole in the bottom part is possible to be implemented by various methods. The most economical and less labour-intensive is their plastic forming. In this way, such type of products may be produced by drawing, extruding, plugging. When the products have a relatively large wall thickness, the backward extrusion process is most applicable. It is interesting to use a cone-shaped punch to perform extrusion in a cylindrical matrix without providing a support to the inner surface of the workpiece. The process of backward extrusion is a universal operation of non-cutting shaping, which makes it possible to obtain hollow case products, round and square in plan [1-4]. The non-cutting shaping operation has a number of advantages, the main of which are saving in the workpiece material and favorable mode of deformation in the workpiece being formed during the forming process [5-7]. The process of backward extrusion of a $6 \mathrm{Al}-4 \mathrm{~V}$ alloy pipe workpiece with a cone-shaped punch will be consired in the paper [8-11]. It is assumed that the extrusion operation considered in the article allows manufacturing the elements of fuel lines of special equipment, which are subject to high requirements on weight and strength. On this account, the range of metal materials that can be used for production of such products is limited. A $6 \mathrm{Al}-4 \mathrm{~V}$ titanium alloy that meets the requirements imposed upon the parts was accepted as a workpiece material. The peculiarity of the process under consideration is the fact that the inner surface of the billet under the punch is free, in other words the metal outflow on it is not limited to the tool. Despite the significant number of works devoted to studying the operations of backward extrusion of pipe workpieces with a cone-shaped punch, the aspects of influence of temperature and speed conditions at various combinations of process variables and geometric parameters of the process upon formation of the product geometric characteristics have not been considered in detail. Most of the works are devoted to the research of this operation under cold-deforming conditions. In view of this, it is important to select the process variables to ensure correct geometry of the products.

\section{Setting the research objectives}

Fig. 1 shows a diagram of the process of backward extrusion of a pipe workpiece with dimensions. It is assumed that the forging is made of $6 \mathrm{Al}-4 \mathrm{~V}$ titanium alloy.

To perform the problems put by, DEFORM software was applied using the basic theses of the theory of plasticity of an elasticoplastic, incompressible, hardening material.

The punching temperature range is $20 \ldots 900^{\circ} \mathrm{C}$. The workpiece had the following initial dimensions: $H_{0}=$ $=60 \mathrm{~mm} ; D_{0}=100 \mathrm{~mm} ; D_{1}=80 \mathrm{~mm} ; H_{1}=70 \ldots 100 \mathrm{~mm}$. The punch movement speed has varied in the range from

(c) A. A. Pasynkov, V. I. Tregubov, O. I. Boriskin, 2021 


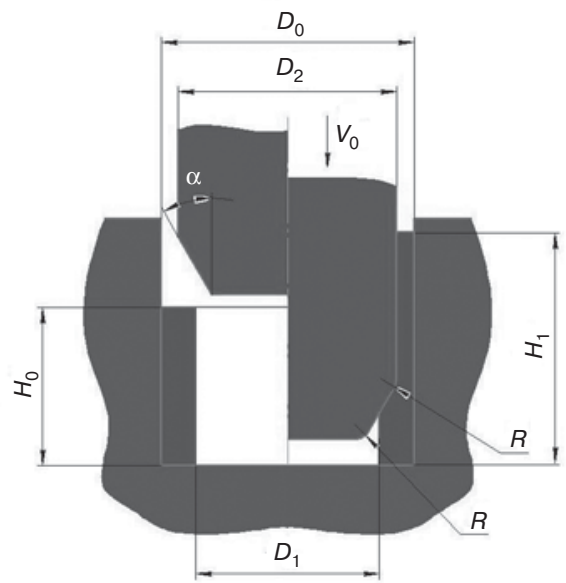

Fig. 1. Diagram of a backward extrusion process

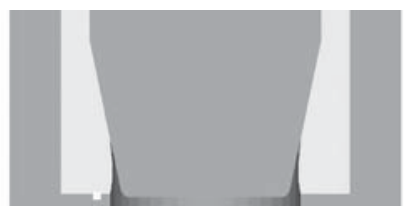

$\alpha=11^{\circ}$

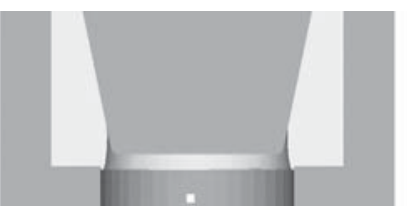

$\alpha=13^{\circ}$

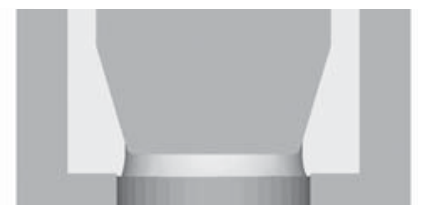

$\alpha=15^{\circ}$
Fig. 2. Diagrams of the backward extrusion process $\left(r=0.5 ; V_{0}=0 \mathrm{~mm} / \mathrm{min} ; \mu=0.25\right)$

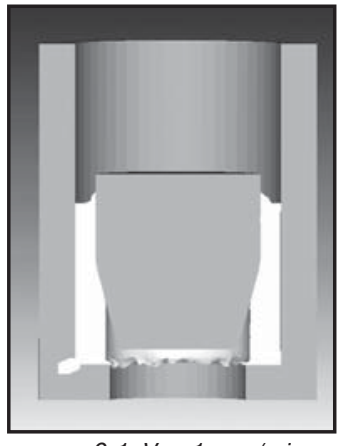

$\mu=0.1, v_{0}=1 \mathrm{~mm} / \mathrm{min}$

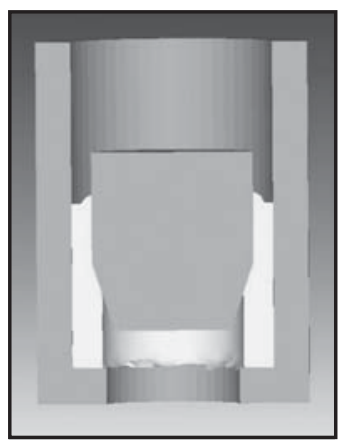

$\mu=0.1, v_{0}=1 \mathrm{~mm} / \mathrm{min}$

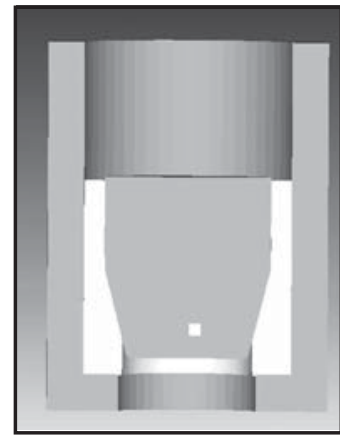

$\mu=0.1, v_{0}=10 \mathrm{~mm} / \mathrm{min}$

a

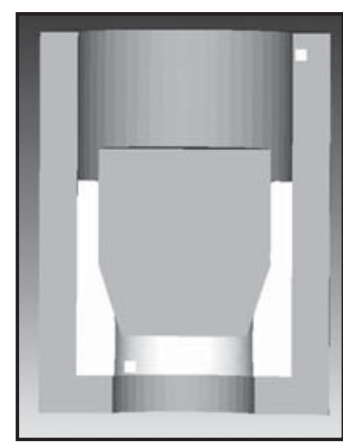

$\mu=0.1, v_{0}=10 \mathrm{~mm} / \mathrm{min}$

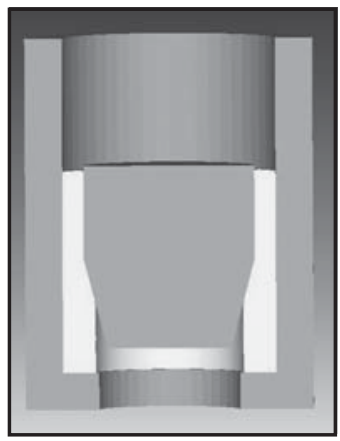

$\mu=0.1, v_{0}=100 \mathrm{~mm} / \mathrm{min}$

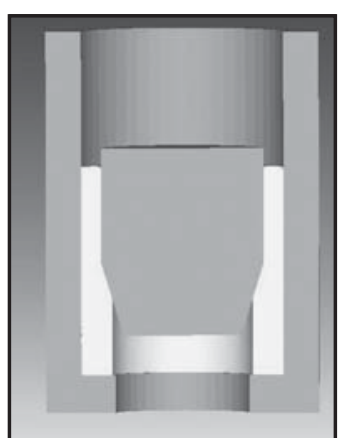

$\mu=0.1, v_{0}=100 \mathrm{~mm} / \mathrm{min}$
Fig. 3. Diagrams of the backward extrusion process at different process variables: $a-\alpha=15^{\circ} ; b-\alpha=19^{\circ}$
1 to $30 \mathrm{~mm} / \mathrm{min}$. The rheological model of the workpiece is elasticoplastic one. The number of final elements of the workpiece grid is $200 \ldots 500$ thous.

Processing of the results of theoretical studies was carried out by methods of mathematical statistics.

\section{Results and discussion}

The reduction which was assumed to be equal to $r=$ $=D_{2}^{2}-D_{1}^{2} / D_{0}^{2}-D_{1}^{2}$ and the punch taper angle $\alpha$ have been chosen as the main parameters that are the criteria for evaluating an influence of the punch geometric parameters and deformation degree upon the process course. In the process of modeling, on combining certain geometric and technological parameters, there is observed the defect formation associated with the loss of stability of the material under punch, i.e., folding.

Fig. 2 presents the process diagrams depicting the final moment of forming, which allow to evaluate the part geometry formation at a reduction value $r=0.5$ and different punch taper angles. It was assumed that the process in the cases shown in Fig. 2 takes place at $900{ }^{\circ} \mathrm{C}$. The friction conditions were taken corresponding to the hot forming process at a constant of friction $\mu=0.25$. The forming velocity $V_{0}=10 \mathrm{~mm} / \mathrm{min}$.

It can be seen from these diagrams that the product inner part geometry loses stability even at minimum taper angles for the considered tool and workpiece sizes, friction value and forming velocities. To determine combination of the process variables at which there is no defect formation, their influence on the product geometry has been studied.

It was established that geometry defects occur with the greatest probability at forming velocities $<3 \mathrm{~mm} / \mathrm{min}$ for reduction values $r=0.4 \ldots 0.6$ and taper angles up to $15^{\circ}$. Forming velocity does not affect the formation of defects for reduction values $r=$ $=0.7 \ldots 0.9$ (the maximum possible taper angle of the tool is $25^{\circ}$ ).

Fig. 3 contains the diagrams, allowing to reveal an impact of friction and forming velocity upon the distortion of an inner surface of the parts at a punching temperature of $900{ }^{\circ} \mathrm{C}$.

It can be seen from the diagrams shown in Fig. 3 that the greatest influence on the workpiece surface folding under punch has either an increase in forming velocity up to $100 \mathrm{~mm} / \mathrm{min}$, or its decrease to $1 \mathrm{~mm} / \mathrm{min}$. In the latter case, an influx of metal on the punch is formed in the product due to the metal flow pattern. Thus, one can increase the allowable taper angles of the tool to $\alpha=25^{\circ}$ by selecting these parameters. 
A series of experiments have been performed to evaluate the forces of the process under investigation. Fig. 4 illustrates the dependence of the extrusion force change on the tool movement speed for $6 \mathrm{Al}-4 \mathrm{~V}$ titanium alloy at different reduction values.

An analysis of the dependence in Fig. 4 permits to draw the following conclusions on the power modes of the process: with increasing forming velocity, strength increases 4 times for reduction with a lower value and 6 times for bigger reduction values; the reduction increase from 0.4 to 0.7 leads to augmentation of deformation forces by $35 \%$ for lower forming velocities and 1.6 times for bigger ones. In addition, it can be noted that the change intensity in the forming forces decreases as the tool movement speed increases.

Statistical simulation of the operation under consideration has been performed by reference to the results of the studies performed. It was established that the force is most influenced by the following factors: reduction $r$; speed of punch movement $V_{0}, \mathrm{~mm} / \mathrm{min}$, taper angle $\alpha$, constant of friction $\mu$.

For statistical investigations, the factor space table has been formed to estimate forces (Table 1) [12-13]. Table 2 represents the planning matrix [12-13].

The uniformity is estimated using the Cochrane's test $(g=0.00355)$. Verification of the resultant models has been fulfilled by applying the Fischer's test $(F=0.73)$. According to the results of statistical modelling, the regression equation was drawn in code and natural values of the factors, respectively:

Table 1

Factor space of force estimation

\begin{tabular}{|l|c|c|c|c|c|}
\hline \multicolumn{4}{|c|}{ Factors } & \multicolumn{3}{c|}{ Levels of factor range } \\
\hline \multicolumn{1}{|c|}{ Factor name } & $\begin{array}{c}\text { Natural value } \\
\text { of the factor }\end{array}$ & $\begin{array}{c}\text { Code value } \\
\text { of the factor }\end{array}$ & $X_{i(\min )}$ & $X_{i 0}$ & $X_{i(\max )}$ \\
\hline $\begin{array}{l}\text { Reduction } \\
\text { The speed of } \\
\text { punch movement }\end{array}$ & $r$ & $X_{1}$ & 0.4 & 0.55 & 0.7 \\
\hline $\begin{array}{l}\text { Taper angle } \\
\text { Constant of fric- } \\
\text { tion }\end{array}$ & $\alpha$ & $X_{2}$ & 1 & 5 & 10 \\
\hline
\end{tabular}

Table 2

Experiment planning matrix

\begin{tabular}{|c|c|c|c|c|c|c|c|c|c|c|c|}
\hline \multirow{2}{*}{$\begin{array}{c}\text { No. } \\
\text { of } \\
\text { experiment }\end{array}$} & \multicolumn{5}{|c|}{ Factor } & \multirow{2}{*}{$\begin{array}{c}\text { No. } \\
\text { of } \\
\text { experiment }\end{array}$} & \multicolumn{5}{|c|}{ Factor } \\
\hline & $x_{0}$ & $X_{1}$ & $x_{2}$ & $x_{3}$ & $X_{4}$ & & $x_{0}$ & $X_{1}$ & $x_{2}$ & $x_{3}$ & $X_{4}$ \\
\hline 1 & + & - & - & - & - & 9 & + & - & - & - & + \\
\hline 2 & + & + & - & - & - & 10 & + & + & - & - & + \\
\hline 3 & + & - & + & - & - & 11 & + & - & + & - & + \\
\hline 4 & + & + & + & - & - & 12 & + & + & + & - & + \\
\hline 5 & + & - & - & + & - & 13 & + & - & - & + & + \\
\hline 6 & + & + & - & + & - & 14 & + & + & - & + & + \\
\hline 7 & + & - & + & + & - & 15 & + & - & + & + & + \\
\hline 8 & + & + & + & + & - & 16 & + & + & + & + & + \\
\hline
\end{tabular}
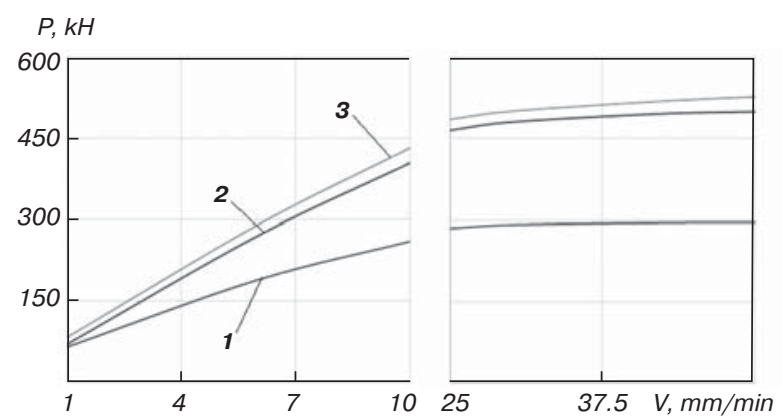

Fig. 4. The extrusion force dependence on the forming velocity: $1-r=0.4 ; 2-r=0.45 ; 3-r=0.7$

$$
\begin{aligned}
& y=215.98+54.94 X_{1}+149.83 X_{2}+12.25 X_{3}+ \\
& +14.46 X_{4}+46.89 X_{12}+9.99 X_{24} ; \\
& P=20.82-24.48 r-9.27 V+1.22 \alpha+19.72 \mu+ \\
& +78.15 r V+24.97 V \mu .
\end{aligned}
$$

The resulting equations are the expressions convenient for practical use; they allow determining the strength of the process under study depending on the most important factors. Fig. 5 illustrates the force dependence on reduction, speed and taper angle of the tool.

As can be seen from Fig. 5, the greatest action on the growth of forces is exerted by an increase in the forming velocity and reduction value. The intensity of the force growth increases especially at large values of these parameters. For example, the reduction increase from 0.3 to 0.9 leads to the force growth by 3.5 times at the forming velocity $V_{0}=10 \mathrm{~mm} / \mathrm{min}$. The force increases by 2 times at the forming velocity
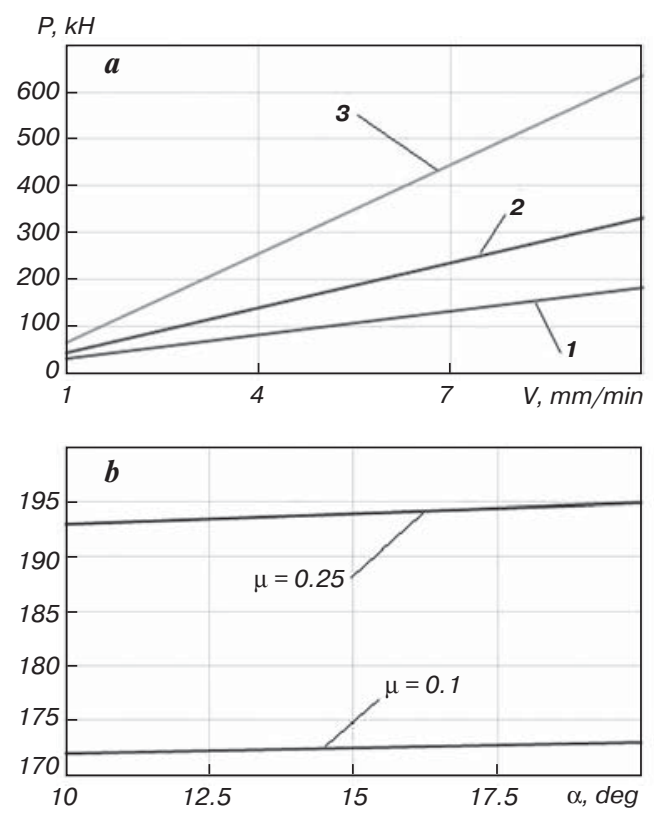

Fig. 5. The extrusion force dependence on the forming velocity $(a)$ and the tool taper angle $(b)$ : $1-r=0.3 ; 2-r=0.5 ; 3-r=0.9$ 
$V_{0}=1 \mathrm{~mm} / \mathrm{min}$. Changing the taper angle and friction does not affect the process force so much. In general, the resultant dependence may be used for designing the technologies of extrusion with a cone-shaped tool made of titanium alloy.

\section{Conclusions}

1. The mode of isothermal extrusion at low tool movement speeds allows the deformation forces to be reduced greatly. At the same time, the reduction of forming velovities complicates metal flow, i.e. the provision of creeping flow conditions creates prerequisites to the metal flowing into the under-punch zone, and thus the billet gets geometry defects. For $6 \mathrm{Al}-4 \mathrm{~V}$ alloy, the forming velocity minimum value, which allows to exclude such a defect formation, is $5 \mathrm{~mm} / \mathrm{min}$. In the course of the research, such ratios of sizes and process variables were determined at which there is no defect formation. For reduction values of 0.4 , minimal defect formation is observed at angles of $10 \ldots 13^{\circ}$ and forming velocities of $3 \ldots .5 \mathrm{~mm} / \mathrm{min}$. At reductions of $0.5 \ldots 0.7$, the angles of $14 \ldots 16^{\circ}$ and forming velocities of $1 \ldots 3 \mathrm{~mm} / \mathrm{min}$ are rational.

2. The process under study is complex in terms of obtaining the product geometry without defects. The greatest influence on folding under the deforming tool is exerted by the taper angle and tool movement speed. Moreover, for each reduction value there is its own allowable taper angle.

3. The proposed process flowsheet of manufacturing the cylindrical case products is expected to reduce the production complexity by $10 . . .20 \%$ (due to the exclusion of additional operating steps and further machining), increase the strength characteristics by $10 \ldots 30 \%$ (it is assumed that favorable stress and structure of the material are formed in the product by means of plastic deformation in isothermal forming; due to the fact that the inner surface of the products does not require machining, its quality increases), reduce metal consumption during the complete cycle of manufacturing products by $20 . . .40 \%$ (owing to the exclusion of operating steps with machining). Thus, the use of the technologies of isothermal forming of high-strength alloys will primarily allow to obtain articles with better mechanical and strength properites, as well as significantly reduce the material costs of their manufacture by saving in metal.

This work was supported by grants NSh-2601.2020.8 (HW-2601.2020.8) .

\section{References}

1. Uniksov E. P., Johnson W., Kolmogorov V. L. et al. Theory of Plastic Deformations of Metals. Moscow : Mashinostroeniye, 1983.598 p.

2. Zhichao Sun, Jing Cao, Huili Wu, Zhikun Yin. Inhomogeneous Deformation Law in Forming of Multi-Cavity Parts under Complex Loading Path. Journal of Materials Processing Technology. 2018. Vol. 254. pp. 179-192.

3. Springer P., Prahl U. Characterisation of Mechanical Behavior of 18CrNiMo7-6 Steel with and Without under Warm Forging Conditions Through Processing Maps Analysis. Journal of Materials Processing Technology. 2016. Vol. 237. pp. 216-234.

4. Zhengyang Cai, Min Wan, Zhigang Liu, Xiangdong Wu, Bolin Ma, Cheng Cheng. Thermal-Mechanical Behaviors of DualPhase Steel Sheet under Warm-Forming Conditions. International Journal of Mechanical Sciences. 2017. Vol. 126. pp. 79-94.

5. Kräusel V., Birnbaum P., Kunke A., Wertheim R. Metastable Material Conditions for Forming of Sheet Metal Parts Combined with Thermomechanical Treatment. CIRP Annals. 2016. Vol. 65, Iss. 1. pp. 301-304.

6. Aksenov S. A., Chumachenko E. N., Kolesnikov A. V., Osipov S. A. Determination of Optimal Gas Forming Conditions from Free Bulging Tests at Constant Pressure. Journal of Materials Processing Technology. 2015. Vol. 217. pp. 158-164.

7. Kyung-Hun Leea, Byung-Min Kim. Advanced Feasible Forming Condition for Reducing Ring Spreads in Radial-Axial Ring Rolling. International Journal of Mechanical Sciences. 2013. Vol. 76. pp. 21-32.

8. Malinin N. N. Creep in Metal Working. Moscow : Mashinostroenie. 1986. 216 p.

9. Pasynkov A. A., Boriskin O. I., Larin S. N. Theoretical Researches on Operation of Isothermal Distribution of Tubes from Difficult-to-Form Non-Ferrous Alloys in Conditions of a Short-Term Creep. Tsvetnye Metally. 2018. No. 3. pp. 80-84. DOI: $10.17580 /$ tsm.2018.03.12

10. Larin S. N., Pasynkov A. A. Analysis of Forming Properties During the Isothermal Upsetting of Cylindrical Workpieces in the Viscous-Plasticity Mode. IOP Conference Series: Materials Science and Engineering. Vol. 441. 012026. DOI: $10.1088 / 1757-899 x / 441 / 1 / 012026$

11. Alves L. M., Afonso R. M., Silva C. M. A., Martins P. A. F. Boss Forming of Annular Flanges in Thin-Walled Tubes. Journal of Materials Processing Technology. 2017. Vol. 250. pp. 182-189.

12. Panfilov G. V., Nedoshivin S. V., Lazarev A. A. Active Statistical Analysis of Systems with Theoretical Models for the Conduct of Machine Experiment. Izvestiya Tula State University: Technical Sciences Series. 2014. No. 5. pp. 98-112.

13. Panfilov G. V., Nedoshivin S. V., Perminov D. A. Application Statistical Machine Experiment for Investigating Theoretical Models Stamping Cores Bullets. Izvestiya Tula State University: Technical Sciences Series. 2014. No. 6. pp. 61-73. 